\title{
Contribuições da gestão por competências na administração pública: um estudo no Instituto Brasileiro de Geografia e Estatística da Paraíba
}

A eficiência é um dos princípios constitucionais que dirige a atividade da Administração Pública. Embora tenha uma face de racionalização dos gastos, a ideia de eficiência também exige o aperfeiçoamento do desempenho das instituiçães públicas. Essa busca por melhoria no desempenho tem ocorrido no contexto da Nova Gestão Pública, a qual preconiza a utilização de ferramentas da gestão privada que possam ser úteis à realidade da administração pública. Nesse sentido, tem se destacado a utilização da gestão por competências como instrumento apto a incrementar a administração das organizações públicas. A presente pesquisa teve como objetivo principal identificar quais as contribuições da gestão por competências ao desempenho do IBGE na Paraíba. Tratou-se de uma pesquisa de campo do tipo exploratório-descritiva, que partiu de uma abordagem qualitativa e utilizou, para o levantamento de dados, observação direta, pesquisa documental e entrevistas semiestruturadas com servidores que ocupam posições gerenciais na instituição estudada. Após a análise dos dados, os resultados da pesquisa indicaram que os principais embaraços ao desempenho do IBGE na Paraíba estão relacionados à forma como a organização enxerga e gerencia seus servidores. Também foi possível mapear as competências individuais e organizacionais fundamentais ao cumprimento da missão institucional da organização estudada. Ao final, foram apresentadas proposições que têm o condão de melhorar a gestão de pessoas e o desempenho no ambiente da pesquisa, por meio de intervenções que coloquem em prática as ideias da gestão por competências no órgão.

Palavras-chave: Competências; Eficiência; Desempenho.

\section{Contributions of competency management in public administration: a study at the Brazilian Institute of Geography and Statistics in Paraíba}

\begin{abstract}
Efficiency is one of the constitutional principles that guides the activity of Public Administration. Although it has a rationalization side of spending, the idea of efficiency also requires an improvement in the performance of public institutions. This search for improvement in performance has occurred in the context of the New Public Management, which stimulates the use of private management tools that may be useful to the reality of public administration. In this sense, the use of competency management as an instrument to increase the administration of public organizations has been highlighted. The main objective of this research was to identify the contributions of competency management to the performance of IBGE in Paraiba. This was an exploratory-descriptive field research, which started from a qualitative approach and used, for data collection, direct observation, documentary research and semi-structured interviews with employees who occupy management positions in the studied institution. After analyzing the data, the research results indicated that the main constraints to IBGE's performance in with employees who occupy management positions in the studied institution. After analyzing the data, the research results indicated that the main constraints to lBGE's performance in the institutional mission of the studied organization. At the end, proposals were presented that could improve people management and performance in the research environment, through interventions that put into practice the ideas of competency management in the institution.
\end{abstract}

Keywords: Competencies; Efficiency; Performance.

Topic: Recursos Humanos

Reviewed anonymously in the process of blind peer.

Hélio Santa Cruz Almeida Neto (iD

Universidade Federal de Campina Grande, Brasil

http://lattes.cnpq.br/9055243310349251

http://orcid.org/0000-0001-6132-535X

heliosantacruz@hotmail.com

Maria de Fátima Nóbrega Barbosa (ic

Universidade Federal de Campina Grande, Brasil

http://lattes.cnpq.br/8262057016878547

http://orcid.org/0000-0003-3415-8829

mfnobregabarbosa@gmail.com

Erivaldo Moreira Barbosa (iD)

Universidade Federal de Campina Grande, Brasil

http://lattes.cnpq.br/0405256524786499

http://orcid.org/0000-0001-7479-1827

erifat@terra.com.br
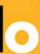

DOI: 10.6008/CBPC2179-684X.2020.003.0005
Received: 10/06/2020

Approved: 29/07/2020
Referencing this:

ALMEIDA NETO, H. S. C.; BARBOSA, M. F. N., BARBOSA, E. M. Contribuições da gestão por competências na administração pública: um estudo no Instituto Brasileiro de Geografia e Estatística da Paraíba. Revista Brasileira de Administração Científica, v.11, n.3, p.65-81, 2020. DOI: http://doi.org/10.6008/CBPC2179-684X.2020.003.0005 


\section{INTRODUÇÃO}

Em virtude das crises política e econômica que acometem o país, o Brasil enfrenta atualmente um notável debate sobre tamanho e função do Estado. Essa não é uma discussão nova, mas que ganha destaque nos momentos em que o Estado dá sinais de esgotamento no cumprimento de suas funções. Independentemente da posição adotada, parece haver um consenso: o Estado precisa ser eficiente.

As ações estatais são efetuadas por meio do governo e da administração pública. Destes é esperado, como consequência do dever de eficiência, um desempenho elevado, que garanta a maior efetividade do bem-estar da população pelo menor custo possível. No Brasil, a complexidade da administração pública é forjada pela escassez de recursos, pela grandiosidade da máquina pública e pela cultura, historicamente tolerante com o alto nível de desonestidade - muitas vezes escondida por trás do eufemismo 'jeitinho brasileiro' - presente nas esferas pública e privada.

Ao longo do tempo, a Administração Pública tem sido guiada por paradigmas que influenciam o modo como ela é enxergada e orientada. Inicialmente, tinha-se uma administração predominantemente patrimonial, na qual os interesses públicos eram usurpados por grupos privados. Em seguida, para sobrepujar o patrimonialismo, foram implantadas as ideias da burocracia, modelo de organização racional-legal idealizado por Max Weber. Mas esse paradigma trouxe muitas disfunções, o que provocou a implantação de um terceiro arquétipo, a Administração Pública Gerencial ou Nova Gestão Pública (NGP). Esses paradigmas não excluem completamente a existência do outro, sendo possível perceber características de todos no atual momento da administração pública brasileira.

A NGP enfatiza a orientação para resultados e, para tanto, importa iniciativas e ferramentas exitosas da gestão privada. Uma dessas iniciativas é a gestão por competências, instituída de maneira formal na administração pública brasileira através do Decreto Federal № 5.707/2006. O referido decreto conceitua gestão por competências como a administração da capacitação direcionada para o desenvolvimento do conjunto de conhecimentos, habilidades e atitudes necessárias ao desempenho das funções dos servidores, visando ao alcance dos objetivos da instituição. A gestão por competências, em visto disso, é considerada uma das ferramentas alinhadas com os valores da administração pública gerencial e útil ao propósito de elevar o desempenho da máquina pública. Vale ressaltar que o referido decreto foi revogado pelo Decreto Federal no 9.991, de 28 de agosto 2019 (BRASIL, 2019), o qual em seu Art. 1 ㅇ dispõe sobre a Política Nacional de Desenvolvimento de Pessoas - PNDP, com o objetivo de promover o desenvolvimento dos servidores públicos nas competências necessárias à consecução da excelência na atuação dos órgãos e das entidades da administração pública federal direta, autárquica e fundacional.

Importante mencionar que a eficiência é um dos princípios constitucionais impostos à Administração Pública. Embora seja bastante lembrada pela ideia de racionalidade e economicidade que impõe ao gasto público, o princípio da eficiência também significa que as instituições públicas devem buscar o aperfeiçoamento da gestão e o alcance de desempenho superior.

Nesse sentido, a gestão por competências tem sido ferramenta útil a conferir mais efetividade à 
gestão de pessoas e, por conseguinte, à melhoria do desempenho no setor público. Esse instrumento tornase ainda mais útil quando se percebe ser comum que os servidores públicos sejam bastante qualificados, mas tenham o potencial para o trabalho desperdiçado, em virtude do desenho ultrapassado que vigora na gestão de pessoas nas organizações públicas.

Para que as demandas da sociedade sejam atendidas, em um cenário de restrições fiscais, só resta uma alternativa aos administradores públicos: aperfeiçoar o desempenho da gestão, elevando a qualidade e a produtividade do setor público. Para tanto, o Estado precisa buscar iniciativas que fomentem a melhoria do desempenho em suas instituições. A Fundação Instituto Brasileiro de Geografia e Estatística (IBGE) é uma autarquia fundacional, cuja existência atende à previsão constitucional que confere à União a competência para organizar e manter os serviços oficiais de estatística, geografia, geologia e cartografia de âmbito nacional.

A fim de atingir seu propósito, o IBGE possui uma capilaridade destacada no serviço público, com atuação em todo o território nacional. Na Paraíba, o IBGE conta com uma sede estadual e agências de coletas estrategicamente distribuídas pelo estado. Por estar inserido no contexto da Administração Pública e pela relevância do serviço que lhe compete no desenho do Estado brasileiro, do IBGE espera-se atuação eficiente e de desempenho elevado, garantindo que a missão institucional seja cumprida.

Diante desse cenário, foi possível formular o seguinte problema de pesquisa: como a gestão por competências pode contribuir com o desempenho da Unidade Estadual do IBGE na Paraíba?. Considerando a introdução ao tema e o problema de pesquisa levantado, foi estabelecido o seguinte objetivo para o presente trabalho: analisar as possíveis contribuições da gestão por competências ao desempenho da Unidade Estadual do IBGE na Paraíba.

\section{REVISÃO TEÓRICA}

\section{Eficiência e Desempenho na Administração Pública}

Frequentemente, a administração pública é comparada à gestão privada. No senso comum, a gestão privada é mais eficiente e exitosa, enquanto a administração pública tem sua imagem atrelada à ineficiência, burocracia e ausência de resultados. Para Ghelman et al. (2006), a administração pública pode e deve se inspirar no modelo de gestão privada, mas nunca deve perder de perspectiva que enquanto o setor privado visa à maximização do lucro, o setor público tem como objetivo o cumprimento de sua função social.

Pereira (2016), por sua vez, não enxerga sentido nessa comparação. É que a todas as iniciativas da gestão privada (melhorar processos, atender bem os clientes, ser eficiente) têm como finalidade o incremento do resultado financeiro. Por mais difícil que isso seja, trata-se de propósito simples. Já a gestão pública não se restringe apenas aos padrões de eficiência e eficácia, a melhorar processos ou a atender bem (embora esses fatores sejam bastante relevantes), mas deve obediência também a padrões de legalidade e legitimidade, além de outros valores que transcendem o contexto dos negócios privados.

Em outras palavras, a administração pública não é somente a gestão interna da máquina pública, 
mas a administração de um contexto sociopolítico complexo, que ultrapassa as fronteiras dos órgãos públicos e deve obediência a severos princípios constitucionalmente estabelecidos. Apesar desse contexto desafiador, é fato que a administração pública deve agir eficientemente. Desejo antigo da sociedade, esse mandamento não estava no texto original da Carta Magna, mas tornou-se princípio constitucional a partir da Emenda Constitucional no 19/1998.

Para Marinela (2017), a eficiência, enquanto princípio, demanda da administração uma atuação com presteza, perfeição e rendimento funcional. Já Pereira (2016) afirma que a eficiência se refere ao esforço abrangente da organização no tocante à aplicação e ao melhor proveito dos recursos, comparando com os resultados obtidos. Uma organização é eficiente quando melhora a relação custo/produto.

Considerando a obrigatoriedade da eficiência e o contexto de transformação da administração pública nos últimos anos, é possível observar que há uma incessante necessidade de melhorar a máquina pública. Esse contexto tem demandado reflexões e ações que elevem o desempenho da administração pública a um patamar superior. É por esse motivo que a administração pública tem implantado ferramentas e modelos, muitas vezes oriundos da gestão privada, a fim de produzir resultados mais próximos dos demandados pela sociedade.

Como visto, a eficiência é o passo inicial na busca de uma administração pública melhor. Todavia, a eficiência não pode se restringir ao conceito de economicidade. É necessário que a administração pública se preocupe com os resultados e com o impacto de suas atividades. Organizações não existem por acaso, mas para cumprir objetivos específicos para os quais foram criadas. Destarte, uma das manifestações da eficiência é o bom desempenho.

Malheiros et al. (2014) afirmam que desempenho é a mensuração do rendimento de algo ou alguém, ou seja, são as ações que pessoas ou organizações apresentam para alcançar objetivos estabelecidos previamente. Diante da necessidade de medir as lacunas entre o esperado e o realizado, tornou-se comum avaliar o desempenho de instituições e das pessoas. A tentativa de garantir que as atividades sejam realizadas da forma como foram planejadas, gerando com isso o resultado esperado pela organização, é a síntese do objetivo da avaliação do desempenho.

Em um ambiente de busca por maximização dos resultados, ferramentas de gestão do desempenho capazes de integrar estratégia, aprendizagem, competências e indicadores quantitativos e qualitativos são bastante desejados, mas difíceis de encontrar. Por causa dessa dificuldade, organizações têm unido práticas de gestão modernas e eficazes em torno de um sistema dinâmico e estratégico, construindo um modelo que promova, de fato, a melhoria do desempenho e o desenvolvimento profissional e organizacional. A gestão por competências é uma dessas ferramentas (BRANDÃO et al., 2008).

\section{Gestão por Competências}

O debate acerca da gestão por competências tem lugar de destaque nas discussões que envolvem desempenho e excelência organizacional. O conceito de competência, ao mesmo tempo em que é bastante empregado, é um dos mais abrangentes no referencial teórico da administração. Dessa maneira, faz-se 
necessário estabelecer um contorno mínimo acerca do assunto, de forma que seja facilitada a compreensão da pesquisa.

Fleury et al. (2001) apresenta competência como um conjunto de conhecimentos, habilidade e atitudes - capacidades humanas, portanto - que explicam um alto desempenho. Não se trata, porém, de um estoque limitado de conhecimentos teóricos e empíricos sem utilidade detidos por um indivíduo, mas sim da própria inteligência prática para situações que se apoiam sobre os conhecimentos adquiridos e os transformam em resultados com tanto mais força quanto maior forem a complexidade das situações. Ou seja, o conceito de competência está diretamente ligado a um exercício de tarefas.

Segundo Ferreira (2015), competência é a capacidade de mobilizar um conjunto de recursos cognitivos (saberes, capacidades, informações, etc.) para solucionar adequadamente uma série de problemas. Reflete os conhecimentos, as habilidades e as atitudes que precisam ser colocadas em prática a fim de alcançar um determinado objetivo. Dito de outra forma, competência é o agir responsável e reconhecido, que implica mobilizar, integrar, transferir conhecimentos, recursos, habilidades, que agreguem valor econômico à organização e valor social do indivíduo.

No contexto das organizações, de acordo com Carbone et al. (2016), as competências funcionam como diferencial competitivo. Se presentes e entregues por seus portadores ou pela organização, diferenciam e impulsionam os negócios. Atualmente, os indivíduos e suas competências são os elementos centrais da diferenciação estratégica, os verdadeiros pilares de vantagem competitiva sustentável. (CARBONE et al., 2016).

O contexto atual, caracterizado por dinamismo, transformações constantes e competitividade, demanda adaptabilidade e capacidade de inovação das organizações, que lhes permitam melhorar continuamente seu desempenho. Se antes a função de gerenciar os recursos humanos era relegada ao departamento de pessoal, hoje, cada vez mais, as organizações modernizam essa área da gestão, a fim de inclui-las na estratégia do negócio. Pessoas deixaram de ser contadas como meros recursos e passaram a ser reconhecidas como fator crítico de sucesso em uma organização.

Segundo Brandão et al. (2007), a gestão por competências se insere entre os modelos gerenciais aptos a atingir esse alto desempenho desejado, influenciando a melhora tanto do desempenho profissional (individual) quanto do organizacional. Como certos recursos são determinantes do sucesso da organização, esse modelo de gestão tem a expectativa de integrar e orientar esforços, notadamente referente à gestão de pessoas, objetivando manter e potencializar as competências críticas ao sucesso organizacional.

Para Carbone et al. (2016), a gestão por competências é um modelo que orienta a organização para o cliente, buscando gerar resultados sustentáveis através do constante desenvolvimento das competências de pessoas, equipes de trabalho e unidades produtivas. Dito de outra forma, um relevante sistema de informações estratégicas sobre as competências necessárias e as existentes em um negócio, orientando as ações de desenvolvimento profissional e organizacional na direção correta. 


\section{METODOLOGIA}

Considerando o problema da pesquisa e o objetivo proposto pelo trabalho, o estudo de caso foi eleito o método de pesquisa mais adequado, por investigar empiricamente um fenômeno contemporâneo dentro de um contexto real (YIN, 2015). Tratou-se de pesquisa de campo do tipo exploratório-descritiva e com análise qualitativa, construída a partir de abordagem que procurou compreender o fenômeno social estudado de maneira naturalística e interpretativa (TAKAHASHI, 2013). Foram utilizadas múltiplas técnicas de coleta de dados, tais como a pesquisa documental (sobretudo nos documentos estratégicos da organização), a aplicação de entrevistas e a observação direta, triangulação que contribuiu para adequada análise do fenômeno. Dessa forma, garantiu-se a profundidade necessária ao estudo e credibilidade aos resultados (GIL, 2017).

Dentro do universo da pesquisa, os sujeitos foram eleitos em amostra não probabilística pelos critérios de acessibilidade e tipicidade, tendo sido escolhidos entre os servidores efetivos do IBGE na Paraíba que ocupam cargos e/ou funções gerenciais. Por conveniência, foram excluídos os participantes que não pertenciam às repartições de João Pessoa e Campina Grande. Essa escolha em nada prejudicou a representatividade da amostra, visto que a maioria dos ocupantes de posições gerenciais está concentrada nessas duas cidades, que conjuntamente representam mais de $70 \%$ do trabalho do IBGE na Paraíba. (VERGARA, 2016).

A partir desse refino, chegou-se ao número potencial de 24 participantes. Desses, 6 se recusaram ou não puderam - por limitações de agenda, férias ou viagens a trabalho - envolver-se com a pesquisa, definindo em 18 o total de indivíduos respondentes. Todos os respondentes foram identificados por 'entrevistado' - independentemente do gênero com o qual se identificam - seguido de número cardinal, de 01 a 18, para diferenciá-los. Dessa forma, preservou-se a identidade dos participantes.

Em seguida, foram realizadas entrevistas em profundidade para captar a experiência e impressões dos servidores participantes acerca de fatores pertinentes ao desempenho do IBGE na Paraíba e à gestão por competências. As entrevistas foram individuais, presenciais e semiestruturadas. A primeira serviu como teste piloto para utilização do roteiro. Como não foram observadas dificuldades relevantes nesse momento, o roteiro foi preservado sem alterações e foi dado seguimento às demais entrevistas.

Os áudios, com a autorização prévia dos participantes, foram gravados e transcritos. A transcrição foi feita logo após a entrevista, para que não ocorresse perda da essência do que foi dito, e serviu para a fase de análise e interpretação dos dados coletados. Concluída a transcrição das entrevistas, foi realizada uma síntese do conjunto das discussões para a análise. Por ocasião da revisão bibliográfica e da pesquisa documental foi possível identificar os grandes temas relevantes ao desempenho do IBGE na Paraíba. As entrevistas permitiram alcançar uma variedade de impressões e percepções do grupo acerca das variáveis do estudo.

De acordo com Bardin (2009), a análise de conteúdo é procedimento que permite análise sistemática e objetiva do conteúdo manifesto na comunicação, possibilitando a compreensão do pensamento do 
entrevistado por meio do conteúdo expresso no texto. No caso específico dessa pesquisa, a análise de conteúdo ocorreu mediante a transcrição das entrevistas. Dessa forma, o conteúdo das respostas transcritas foi organizado em categorias para orientar a interpretação. As categorias estabelecidas foram: estratégia, eficiência e gestão de pessoas.

A pesquisa foi aprovada após avaliação do Comitê de Ética em Pesquisa (CEP) da Universidade Federal de Campina Grande, garantindo que todas as exigências legais e éticas foram respeitadas na confecção do trabalho. Também houve autorização expressa e formal do IBGE para que a pesquisa fosse realizada em uma de suas unidades, de modo que somente após essas permissões as entrevistas foram realizadas.

\section{RESULTADOS E DISCUSSÃO}

O IBGE é uma fundação pública que faz parte da Administração Pública Federal. O órgão se constitui no principal provedor de dados e informações do país, sendo que o produto do seu trabalho é útil e relevante para os diversos segmentos da sociedade civil, sustentando a elaboração e gestão de políticas públicas nos âmbitos federal, estadual e municipal.

Na Paraíba, o IBGE mantém repartições de dois tipos. Há a Unidade Estadual, localizada na capital e que funciona como a sede da instituição no estado. E há também 12 Agências de Coleta de Dados, distribuídas no território paraibano da seguinte forma: duas em João Pessoa e as demais nas cidades de Campina Grande, Itabaiana, Guarabira, Areia, Sumé, Patos, Santa Luzia, Itaporanga, Pombal e Sousa. Cada cidade que sedia uma agência de coleta funciona como um polo que abrange outros municípios das proximidades, de modo que o estado todo está coberto pela atividade da instituição. A partir da pesquisa em documentos estratégicos da organização, foi possível identificar pontos relevantes ao desempenho da instituição no âmbito estadual, o que orientou a elaboração das perguntas e a posterior análise de conteúdo.

\section{Estratégia}

Ao definir o que pretendem alcançar, as instituições fazem escolhas que moldam as suas identidades. Nesse sentido, as organizações têm optado por descrever elementos que comuniquem, ao público interessado, a trajetória que pretendem seguir. Instituições, porém, são conceitos abstratos. Na prática, são formadas por grupos de pessoas intrinsecamente diferentes. Precisam, portanto, encontrar pontos de unidade a fim de caminhar para uma mesma direção (OLIVEIRA et al., 2014).

Assim, é importante que as pessoas de uma organização conheçam e acreditem na estratégia estabelecida. Partindo dessa premissa, foi identificada como ponto relevante ao desempenho do IBGE na Paraíba a categoria estratégia, explorada a seguir. Essa categoria identificou o nível de conhecimento dos servidores acerca da estratégia do IBGE, notadamente do seu plano estratégico.

Não há dúvidas que a internalização da estratégia é fator de grande relevância para o desempenho da instituição. Como as entrevistas envolveram apenas servidores em funções gerenciais do IBGE na Paraíba, esperavam-se respostas afirmativas quando os entrevistados foram questionados se tinham conhecimento 
acerca do planejamento estratégico da organização. Porém, esse não foi o resultado. A maioria dos servidores afirmou que não tem conhecimento suficiente acerca do assunto.

Como em outras instituições, há muitas decisões unilaterais no IBGE, de modo que os servidores e até líderes não têm conhecimento sobre o plano estratégico, nem os objetivos da instituição, nem sabem o porquê estarem fazendo aquilo. (Entrevistado 11)

De certa forma, foi possível perceber que esse desinteresse é fruto da percepção de que o conhecimento da estratégia tem pouca relação com o trabalho do cotidiano. Pelas respostas, também foi possível inferir que no IBGE/PB predomina uma visão extremamente fragmentada da instituição. É como se, para esses servidores e suas equipes, a instituição se resumisse ao próprio setor, inexistindo perspectiva holística da organização. Também há a percepção de que a falta de comunicação da estratégia é uma falha da alta administração.

\section{Eficiência}

A eficiência, além de princípio constitucional, é um valor de grande relevância para o IBGE. É uma das dimensões estratégicas que abrange sua atuação e uma das faces que revela o desempenho da organização. Dada essa importância, a eficiência emergiu como uma das categorias a ser analisada, pela relevância que possui no desempenho da instituição. Os recursos recebidos atualmente pelo IBGE diminuíram, em valores reais, $30 \%$ desde 2009. Ademais, o órgão trabalha com carreiras defasadas e redução do quadro de funcionários. Em que pese esse quadro, o órgão produz duas vezes mais pesquisa que há dez anos (CASTRO, 2016).

Pode-se ver, portanto, que, mais que um objetivo perseguido, a eficiência é um valor que faz parte da cultura da instituição e também uma necessidade, diante da vultosa diminuição orçamentária ocorrida nos últimos tempos. Convém ressaltar, todavia, que na administração pública, a eficiência não pode ser vista puramente pela maximização da relação entre meios e fins, isto é, dos recursos utilizados em determinada ação e os fins pretendidos com ela. É que a eficiência encontra limites nos demais princípios e normas constitucionais, além de que os efeitos da atividade pública não podem ser mensurados em termos puramente monetários (OLIVEIRA et al., 2014).

Um dos pontos abordados nessa categoria foi o nível de qualidade das pessoas, no sentido da aptidão e adequação das competências de cada servidor ao trabalho que the é confiado. Como os respondentes ocupam posição gerencial, puderam avaliar essa questão com mais propriedade. De modo geral, foi identificada uma lacuna entre aquilo que é cobrado nos concursos públicos e o que é necessário para o exercício da atividade. Ademais, existe desequilíbrio na distribuição de cargos, com grande predominância de servidores de nível médio, que acabam sendo colocados em posições que, em tese, não lhes caberiam.

Quando tem [reposição de pessoal efetivo] é apenas com servidores de nível médio, que têm certa dedicação, a maioria são bons servidores, mas são pessoas que fizeram provas muito simples: português, matemática, geografia e história. (Entrevistado 04)

No tocante à realidade do IBGE, há basicamente duas carreiras de servidores efetivos no órgão, conforme o estabelecido na Lei 11.355/2006 (BRASIL, 2006): uma de nível superior e outra de nível médio. Formalmente, cada um desses cargos tem atribuições específicas, sendo que as tarefas mais analíticas e 
complexas pertencem aos cargos de nível superior e as mais rotineiras e técnicas são responsabilidade dos cargos de nível médio. Porém, essa divisão racional não ocorre no dia a dia.

Na prática, não existe critério válido para essa distribuição. Há casos de servidores de nível médio em posições mais complexas, enquanto há também servidores de nível superior ocupando atividades meramente burocráticas e rotineiras. A própria diretriz do órgão é indutora desse equívoco: enquanto os servidores de nível médio podem ocupar qualquer posto na estrutura estadual do IBGE, os servidores de nível superior ficam restritos a setores específicos na Unidade Estadual. Assim, não é incomum que servidores inexperientes assumam, por exemplo, a liderança em agências de coleta. Não por mérito, mas por estrita necessidade.

Outro fator importante, quando se trata de eficiência, é a medição do desempenho. 0 gerenciamento do desempenho é prática indissociável da visão de futuro da instituição, isto é, do dimensionamento das expectativas dessa organização. Significa dizer que se o desempenho não for gerenciado, a organização também não será administrada adequadamente, visto ser impossível separar essas duas coordenadas (LUCENA, 2012). Nesse sentido, os servidores foram questionados sobre como é medido o resultado do trabalho deles e como eles avaliam essas métricas de desempenho.

Eu acho que essa avaliação de desempenho não ajuda em nada. Aqueles itens são completamente subjetivos e não refletem o desempenho. É um sistema bem antiquado. Até porque só um avalia. O que a gente faz, na prática, é repetir a nota [do semestre anterior]. (Entrevistado 12)

O que se pode ver, conforme fala dos respondentes, é que a avaliação de desempenho individual não tem alcançado utilidade, sendo, na verdade, instrumento bastante criticado pelos servidores e descolado da gestão estratégica do IBGE. Ao abrir mão de medir o desempenho, a instituição deixa de identificar o que faz bem e o que precisa melhorar, além de que não consegue dirigir recursos e dimensionar adequadamente a necessidade de treinamento e desenvolvimento, por exemplo. Se uma pessoa não sabe o que a organização espera de seu trabalho ou se a organização não the fornece os meios adequados para desempenhar esse trabalho, não há como produzir um bom resultado. Dessa forma, o importante não é a mera existência instrumento de avaliação, mas, na verdade, como se dá o processo de gestão de desempenho (BITENCOURT, 2011).

\section{Gestão de pessoas}

De forma geral, a gestão de pessoas no setor público tem assumido formato departamental (setor de pessoal, departamento de recursos humanos, coordenação de gestão de pessoas). Entretanto, essa visão funcional da gestão de pessoas não condiz com as necessidades emergentes da administração pública, dado o contexto de demandas crescentes em quantidade, qualidade e complexidade. A sofisticação na demanda pelos serviços públicos e na atuação das instituições públicas exige atuação compatível das pessoas em termos de desenvolvimento e mobilização das pessoas (BERGUE, 2014). A partir dessa perspectiva, gestão de pessoas foi a categoria final para análise do desempenho do IBGE na Paraíba e para as contribuições da gestão por competências nesse órgão. 
Um dos processos relevantes na gestão estratégica de pessoas, segundo Dutra (2016), é a movimentação de pessoas. Esse processo inclui medidas como captação e internalização de pessoas. Enquanto a captação se refere à atividade da organização para encontrar e estabelecer uma relação de trabalho com pessoas capazes de atender às suas necessidades presentes e futuras, a internalização busca inserir de forma adequada as pessoas na organização, de modo a encaixa-las com o máximo de proveito nas atividades da instituição. Cabe à organização, portanto, selecionar de acordo com as suas necessidades e distribuir as pessoas em postos pertinentes às suas competências.

Nesse sentido, os participantes foram perguntados sobre o critério que balizou a alocação deles e das equipes nos atuais postos de trabalho: análise de perfil e histórico ou atendimento de necessidade circunstancial, independentemente da identificação das competências com o trabalho. De modo geral, eles responderam que essa alocação ocorre pela necessidade do momento, denotando descolamento entre os processos de selecionar e aplicar pessoas com a estratégia da organização.

É pela necessidade imediata. Está precisando de gente ali, manda alguém para lá. Ou então chega gente do concurso e se distribui. Isso sem perguntar as competências de cada um. (Entrevistado 13)

Ao ser guiado pelas circunstâncias na alocação das pessoas, a organização abre mão de colocar em prática sua estratégia e de conseguir o desempenho máximo em atividades que podem ser críticas ao sucesso da organização. Ademais, essa distribuição equivocada de pessoal pode ser fator de má influência na motivação, clima organizacional e no sentido de pertencimento à organização (BITENCOURT, 2011).

As organizações públicas deveriam dedicar mais energia para liderar o processo de aprendizagem em seus espaços, criando ambientes para esse fim no mesmo ritmo que produzem sistemas de informações. Um dos grandes desafios da administração pública é ter iniciativas que permitam o aperfeiçoamento constante dos servidores, de forma a melhorar o serviço público. Não se trata, como se pode pensar, de uma demanda interna do serviço público, mas de uma contribuição à melhoria da competitividade no país e de desenvolvimento sustentável e menos desigual (AMARAL, 2006; BERTOLINI et al., 2013).

Nesse contexto, as pessoas também puderam analisar a forma como a organização tem capacitado e preparado seus servidores não apenas para as atividades do presente, mas também para o futuro, tudo em alinhamento com a estratégia estabelecida. De modo geral, a análise dos respondentes foi de que essas iniciativas não têm sido satisfatórias.

A crítica mais forte que surgiu nesse tópico fez referência ao papel dos setores de Recursos Humanos (RH) no IBGE. Para os participantes, as ações nessa área têm se reduzido a mero papel burocrático, típico da antiga administração de pessoal existente no início da revolução industrial. Inexiste, na visão deles, qualquer ação que valorize e incentive os servidores, conforme os relatos abaixo.

Eu acho que, no geral, os setores de recursos humanos do IBGE funcionam como setores para fazer admissão e desligamento de pessoal, mais voltada para a parte burocrática da coisa. Essa parte de fazer levantamento, visando ao aproveitamento do potencial dos servidores na prática não existe. (Entrevistado 17)

A gestão de pessoas nas organizações públicas não deveria ser atribuição de apenas um setor, mas de todos os agentes públicos. Também não deveria ser responsabilidade apenas dos gestores, mas de cada 
membro da equipe. Essa necessidade é ainda maior quando se percebe que no serviço público tem-se um conjunto heterogêneo de pessoas detentoras de competências em geral bastante superiores àquelas requeridas para a investidura e desempenho do cargo. Destarte, seria necessário que o IBGE elevasse a gestão de pessoas a um protagonismo real, não restrito apenas às suas intenções contidas no plano estratégico (BERGUE, 2014).

Essa tarefa, contudo, não é fácil. De início, caberia fornecer mais autonomia e enriquecimento nas funções dos setores de recursos humanos. É que a abordagem estratégica de desenvolvimento de pessoas tem como pressuposto a existência de certa margem de decisão organizacional para a consideração de alternativas estratégicas para a adequação dos processos de gestão de pessoas aos objetivos da organização. Também passaria por integrar à gestão de pessoas o desenvolvimento estritamente alinhado às necessidades atuais e futuras da organização. Recrutar, selecionar, aplicar e desenvolver pessoas de acordo com os objetivos estratégicos (FONSECA et al., 2013).

Outras queixas dos servidores envolveram a falta de oportunidades para participar de eventos de treinamento e desenvolvimento e acerca do papel da Escola Nacional de Ciências Estatísticas (ENCE) como instrumento de desenvolvimento dos servidores do IBGE na Paraíba. A ENCE é uma Instituição Federal de Ensino Superior que faz parte do IBGE. Além de fornecer cursos para o público externo, a instituição é responsável pelas atividades de capacitação e treinamento de servidores do IBGE. Apesar desse papel, não há qualquer notícia de atividades de desenvolvimento promovidas pela ENCE para os servidores do IBGE na Paraíba, com exceção de cursos EAD (Ensino a Distância). Esses cursos sequer foram mencionados pelos respondentes, o que denota a irrelevância que possui no desenvolvimento dos servidores no âmbito da Paraíba (IBGE, 2017). Se os servidores não têm encontrado suporte na instituição do próprio IBGE, também há pouco acesso - novamente pela restrição orçamentária - dos servidores aos cursos periodicamente oferecidos por escolas do governo, como a Escola Nacional de Administração Pública (ENAP) e a Escola de Administração Fazendária (ESAF).

As organizações costumam contabilizar o custo de desenvolver suas pessoas, mas esquecem-se de mensurar quanto custa não treiná-las adequadamente. Os recursos intelectuais de uma organização se esgotam, a menos que sejam constantemente renovados. Dessa forma, a organização não pode esperar lealdade e capacidade autossustentável de um servidor se ela minar o conhecimento e os talentos de sua força de trabalho (COELHO, 2004).

\section{Proposições}

A partir do levantamento de dados realizado, foi possível constatar oportunidades de melhoria a partir das quais o desempenho do IBGE na Paraíba pode ser incrementado. Foi percebido também que a maior parte dessas oportunidades guarda relação com a gestão de pessoas na organização, de modo que a gestão baseada em competências se apresenta como ferramenta útil a viabilizar esses progressos.

Não se deve acreditar, todavia, que o levantamento de dados nos documentos, entrevistas e observações trouxe à tona apenas pontos fracos da instituição. O foco nos pontos fracos, portanto, decorrem 
apenas da natureza do presente trabalho, direcionado a contribuir com melhorias reais à gestão da organização. Inicialmente, os problemas identificados foram consolidados e agrupados de acordo com as categorias utilizadas na análise de conteúdo, conforme o Quadro 1.

Quadro 1: Oportunidades de melhoria no desempenho do IBGE na Paraíba.

\begin{tabular}{|l|l|}
\hline Categorias & Problemas \\
\hline \multirow{3}{*}{ Estratégia } & - Falta de interesse e conhecimento da estratégia. \\
& - Visão fragmentada e departamentalizada da instituição. \\
& - Comunicação deficiente. \\
& - Ausência de processos de sucessão e risco de quebra de continuidade. \\
\hline \multirow{3}{*}{ Eficiência } & - Divergência entre seleção e aplicação de servidores. \\
& - Falta de critérios na distribuição e desenho dos cargos. \\
& - Descolamento entre a avaliação individual de desempenho e o desempenho da organização. \\
& - Alocação de pessoas com base na necessidade circunstancial. \\
& - Processo de aplicação de pessoas descolado da estratégia organizacional e do desempenho. \\
& - Limitação no acesso a treinamento e desenvolvimento. \\
& - Baixa utilidade da ENCE. \\
& - Atuação dos setores de recursos humanos limitada a atividades burocráticas e de controle. \\
& - Falta de sintonia entre a estratégia e a política de desenvolvimento de pessoas \\
\hline
\end{tabular}

A divisão em categorias teve a utilidade de facilitar a visualização do diagnóstico, tendo em vista que reparte em pedaços menores os problemas a serem enfrentados pela organização. Mas estratégia, eficiência e gestão de pessoas não são elementos estanques. Como a administração é holística, esses componentes são diretamente vinculados e alimentam-se mutuamente. Destarte, ficou perceptível que a maior parte dos problemas identificados converge para o modo como as pessoas são enxergadas pela organização.

Como já mencionado, a gestão por competências serve como modelo para suprir a organização dos conhecimentos, habilidades e atitudes necessárias ao desempenho e ao cumprimento da estratégia. Pela realidade que envolve as organizações públicas na atualidade, o desenvolvimento de profissionais adquiriu peso diferente e a aplicação da gestão por competências tem potencial de influenciar todo o ciclo de ações da gestão de pessoas.

A síntese dos problemas apontados é demonstrada na maneira ultrapassada de gerir pessoas, fruto do esgotamento provocado pela estrutura departamentalizada e pelo desenho pouco fluido de cargos e atribuições. Esse modelo não se coaduna com o cenário atual, que impõe fluidez, estruturas flexíveis e orientação para resultados. Essas mudanças, porém, são de difícil implantação, considerando o cenário e limitações da administração pública. Ainda assim, é possível pontuar intervenções determinadas, factíveis para o IBGE na Paraíba.

Obviamente, não se pretendeu esgotar soluções para todos os problemas da organização. Atingiu-se apenas uma parte deles e, ainda assim, não são soluções únicas, não significando que não haveria outras. Não há dúvidas, porém, de que as proposições aqui apresentadas são factíveis e plenamente úteis à gestão da instituição. Assim, apresentam0se intervenções, dentro do escopo da gestão por competências, que podem ser executadas de modo a melhorar o desempenho do IBGE na Paraíba.

A primeira intervenção seria realizar mapeamento de competências de forma aprofundada e abrangente na organização. É que as competências devidamente mapeadas e descritas servirão como referência para o desempenho desejado pela organização. A gestão por competências permite a definição 
dos padrões de desempenho desejáveis e o simultâneo desenvolvimento das competências que favoreçam o alcance dos resultados esperados (CARBONE et al., 2016).

Mapeadas as competências essenciais ao desempenho do órgão, o passo seguinte é a identificação dos gaps ou lacunas evidenciadas no cotejo entre as competências que são necessárias e aquelas que já existem. Esse processo precisa envolver toda a organização e ser liderado pela alta administração. Não há dúvidas de que uma das fragilidades evidenciada na pesquisa foi o descolamento que existe entre o plano estratégico do IBGE e as atividades do dia a dia, notadamente a realidade da gestão de pessoas no órgão. Embora nos documentos oficiais haja diversas declarações e indicativos de que as pessoas são recursos essenciais na organização, o cotidiano do trabalho aponta para uma realidade diferente da descrita nos papeis.

Nesse sentido, a segunda intervenção seria alinhar a execução da estratégia ao desenvolvimento de competências. Para que as organizações sejam efetivas e apresentem os resultados que dela são esperados, é fundamental que gestores e servidores estejam em sintonia nos propósitos e tenham visão única do que deve ser feito.

Ao esclarecer a estratégia e tendo mapeado as competências, a organização tem a oportunidade de levar todos os servidores a um nível menos díspar de desempenho, além de conseguir padronizar processos e atividades, outra fragilidade identificada a partir do relato dos entrevistados. Essa segunda intervenção também facilita a comunicação da estratégia e a gestão do conhecimento, ao agregar os elementos estratégia, desempenho e competências num ciclo que se retroalimenta constantemente. Ademais, ao investir em competências específicas, a organização estará comunicando o que para ela é importante.

A partir da observação e dos relatos dos entrevistados, foram identificadas fragilidades na maneira como o IBGE na Paraíba seleciona e aloca as pessoas. Embora haja um plano de cargos e carreiras estabelecido, a organização não segue critérios claros no momento de selecionar e distribuir as pessoas entre as diversas funções. O IBGE na Paraíba se notabiliza pelo excesso de servidores de nível médio ocupando funções que não são compatíveis com os cargos que ocupam. O problema, nesse caso, não é a falta de qualificação. A maioria desses servidores tem formação de nível superior, seja com graduação ou até pósgraduação.

O inconveniente, na verdade, é que essas pessoas são selecionadas através de provas com conteúdo bastante simples - o que nivela a seleção por baixo - e depois são alocadas em funções em áreas diferentes e com complexidade bem maior do que se indicava no momento do concurso público. Ao chegarem à organização, são distribuídas não após análise de perfil e competências, mas para atender necessidades circunstanciais do setor que precisa no momento.

Os servidores em cargo de nível superior, por sua vez, muitas vezes estão ocupando postos com nível de exigência aquém da formação e capacidade que possuem. Na prática, não se observa respeito aos desenhos de cargos e competências. Essa realidade denota uma completa falha no planejamento: primeiro, contrata-se; depois é que são levantadas as necessidades do órgão. Os resultados são improviso e baixa eficiência na seleção e alocação de pessoal. Portanto, uma terceira intervenção possível seria selecionar e 


\section{alocar pessoas por competências.}

Como consequência do mapeamento das competências e do alinhamento com a estratégia, o IBGE na Paraíba teria condições de prever melhor a sua necessidade de força de trabalho e selecionar pessoas de acordo com competências. Essa seria, inclusive, uma forma de atacar a carência de pessoal, visto que o órgão chegaria a uma distribuição mais eficiente de seu pessoal, impactando positivamente o desempenho.

O desenvolvimento de pessoas tem sido outro fator descolado da estratégia e do desempenho no IBGE da Paraíba. Queixa frequente dos servidores foi o baixo investimento no desenvolvimento das pessoas do IBGE, sobretudo do pessoal alocado na área administrativa. Embora busque a eficiência e o alto desempenho como valores e afirme que as pessoas são essenciais nesse papel, a organização não tem atrelado o desenvolvimento de seus servidores ao cumprimento da estratégia institucional.

Foi observado, por exemplo, que a ENCE tem sido instituição de pouca utilidade às atividades do IBGE no estado. Nesse sentido, a repartição poderia demandar junto à instituição de ensino ou mesmo por intermédio das diretorias do IBGE que a ENCE formatasse cursos específicos de acordo com a necessidade de atuação no âmbito estadual. Esse fato só reforça a importância do mapeamento das competências e da sintonia que esse processo deve guardar com a estratégia organizacional. Desenvolver pessoas por competências seria a quarta intervenção útil a mitigar os problemas identificados nessa pesquisa.

Por fim, o sistema de avaliação de desempenho no IBGE tem se mostrado inútil. Nesse contexto, queixa relevante dos servidores tem sido a avaliação de desempenho individual, marcada por fatores subjetivos, incompreendidos tanto por líderes quanto por liderados. Como esse processo tem repercussão na remuneração do servidor, dois cenários se repetem: ou o servidor recebe uma boa nota apenas pelo bom relacionamento que tem com o supervisor ou recebe uma nota que não lhe agrada, sem que os motivos sejam devidamente identificados, tendo impacto negativo no salário. De toda forma, esse processo de avaliação de desempenho revela-se um fracasso.

Solução viável, portanto, seria avaliar e remunerar por competência, atrelando a medição do desempenho à gestão por competências. Através dessa quinta intervenção, a organização poderia desdobrar estratégia em competências e estas, em métricas de desempenho, tornando o processo de avaliação justo e útil. Ademais, permitiria a identificação das necessidades de treinamento e desenvolvimento dos servidores. O que se observa, portanto, é que as intervenções propostas formam uma linha racional que eleva as competências à condição de fator essencial ao desempenho.

Dentro das propostas de mudança, os setores de recursos humanos deveriam assumir papel de protagonismo na mudança. Ou seja, essas intervenções passam pela renovação da gestão de pessoas na instituição, trazendo a mentalidade de desempenho e orientação para resultados a todos os servidores e elevando o papel dos recursos humanos de administração de pessoal para a gestão estratégica de pessoas.

Ao final, convém esclarecer que as proposições acima podem enfrentam limitações de duas ordens. Primeiro, algumas das iniciativas podem demandar mudanças organizacionais que extrapolam o limite de atuação e autonomia do IBGE na Paraíba, precisando de aval ou participação da direção do órgão. Segundo, as ideias da gestão por competências podem encontrar resistência e limitações na administração pública, 
notadamente quanto à necessidade de eventuais alterações na legislação e mudança na cultura organizacional. Essas restrições, porém, não devem ser encaradas como impeditivos definitivos às intervenções, mas como instrumentos aptos levantar o debate acerca da gestão e do desempenho nas organizações públicas.

\section{CONCLUSÕES}

De modo geral, a população enxerga a administração pública como um ambiente pouco eficiente e de desempenho limitado. Essa visão é decorrente em grande parte do histórico patrimonialista e burocrático da gestão pública no Brasil. Não se dúvida, portanto, que o Estado precisa ser eficiente. No Brasil, essa necessidade é reforçada pelo contexto de demandas públicas cada vez mais sofisticadas e o orçamento público frequentemente mais restrito, sobretudo quando se considera a crise econômica que o país enfrenta e a recente emenda constitucional que impõe limitação para as despesas públicas. A eficiência, porém, não pode ser enxergada sob um prisma meramente financeiro. Não se trata apenas de gastar menos, mas de conseguir o melhor resultado possível com o orçamento que se impõe. Assim, a outra face da eficiência é enxergada quando as instituições públicas apresentam bom desempenho.

Nesse sentido, é imprescindível que as organizações públicas sejam orientadas para resultados. Se a finalidade do Estado é o bem comum e a administração pública existe como ferramenta para instrumentalizar esse propósito, as organizações não podem ser autocentradas ou descoladas da realidade que as cerca. Dessa forma, cada órgão e instituição da administração pública deve buscar melhorar a gestão de modo a alcançar desempenho superior. O principal insumo para essa melhoria de desempenho são as pessoas. Os servidores públicos são, em regra, bastante preparados e qualificados. Mas é comum que as instituições públicas desperdicem o potencial desses talentos, relegando-os a funções e cargos mal desenhados e gerindo pessoas de uma forma que não mais funciona, diante do contexto que envolve as organizações.

Considerando essa realidade, a pesquisa pretendeu identificar quais contribuições a gestão por competências pode oferecer ao IBGE na Paraíba. O IBGE é órgão que cumpre relevante função no desenho do Estado brasileiro. À organização cabe o papel constitucional de ser o serviço oficial de geografia e estatística do país, o que é sintetizado na missão de retratar o Brasil com as informações necessárias ao conhecimento de sua realidade e ao exercício da cidadania.

A gestão por competências, por sua vez, tem sido enxergada como um instrumento apto a gerir pessoas no atual contexto organizacional. É importante que identifiquem e desenvolvam as competências individuais e organizacionais críticas ao sucesso organizacional. Esse processo deve ser construído em consonância com a estratégia e objetivos estabelecidos a priori nas instituições.

Ao fim do trabalho, pode-se dizer que os objetivos foram atingidos. A partir de estudo localizado no IBGE da Paraíba, foi possível identificar oportunidades de melhoria ao desempenho do órgão e indicar as contribuições oriundas da gestão por competências aplicadas às fragilidades encontradas no processo de pesquisa.

A estratégia do IBGE tem sido restrita aos documentos e alta direção. Os servidores mencionaram 
que o assunto é pouco conhecido por eles. Esse fato é ainda mais importante quando se lembra de que os participantes da pesquisa ocupam posições gerenciais na Paraíba. A gestão de pessoas é descolada da estratégia. Assim, foi identificado que fatores relacionados à gestão estratégica, eficiência e gestão de pessoas são limitadores ao desempenho do IBGE/PB.

Embora separados em categorias distintas, foi possível observar que os pontos fracos identificados guardam relação com a gestão de pessoas no órgão. Embora cite a importância das pessoas, nos documentos estratégicos, o IBGE não tem conseguido implantar gestão que valorize e desenvolva seu pessoal. As proposições, portanto, caminharam no sentido de aplicar as ideias da gestão por competências na instituição estudada, em iniciativas como mapeamento de competências mais aprofundado, alinhamento da estratégia às competências, seleção, desenvolvimento e avaliação por competências.

Apesar dos pontos fracos enxergados, observou-se que o IBGE é organização com gestão e desempenho exemplares no âmbito da administração pública e com uma forte cultura de eficiência. Percebeu-se também que os servidores, em regra, prezam bastante pela instituição e têm bastante interesse em cumprir o trabalho da melhor forma. O trabalho enfrentou algumas limitações, oriundas especialmente das opções metodológicas. Essas limitações, todavia, não comprometeram o alcance do objetivo proposto, de modo que se chegou ao final do trabalho com resultados consistentes e proposições críveis.

Para pesquisas futuras, sugere-se que seja ampliada a investigação de temas na área de gestão de pessoas na administração pública, como motivação, remuneração, qualidade de vida, bem como do estudo dos fatores que podem levar as instituições públicas a obterem desempenho superior. Ademais, é possível e útil a aplicação da presente pesquisa em outras organizações públicas.

\section{REFERÊNCIAS}

AMARAL, H. K.. Desenvolvimento de competências de servidores públicos na administração pública brasileira. Revista do Serviço Público, Brasília, v.57, n.4, p. 549-63, 2006. DOI: https://doi.org/10.21874/rsp.v57i4.211

BARDIN, L.. Análise de conteúdo. Lisboa: 70, 2009.

BERGUE, S. T.. Gestão estratégica de pessoas no setor público. São Paulo: Atlas, 2014.

BERTOLINI, R. V.; ZWICK, E.; BRITO, M. J.. Aprendizagem organizacional socioprática no serviço público: um estudo de caso interpretativo. Revista de Administração Pública, Rio de Janeiro, v.47, n.2, p.493-514, 2013.

BITENCOURT, C.. Gestão contemporânea de pessoas. São Paulo: Bookman, 2011.

BRANDÃO, H. P.; BORGES-ANDRADE, J. E.. Causas e efeitos da expressão de competências no trabalho: para entender melhor a noção de competência. Revista de Administração Mackenzie, v.8, n.3, p.32-49, 2007.

BRANDÃO, H. P.; ZIMMER, M. V.; PEREIRA, C. G.; MARQUES, F.; COSTA, H. V.; CARBONE, P. P.; ALMADA, V. F.. Gestão de desempenho por competências: integrando a gestão por competências, o balanced scorecard e avaliação 360 graus.
Revista de Administração Pública, Rio de Janeiro, v.42, n.5 p.875-98, 2008.

BRASIL. Decreto n.9.991, de 28 de agosto de 2019. Dispõe sobre a Política Nacional de Desenvolvimento de Pessoas da administração pública federal direta, autárquica e fundacional, e regulamenta dispositivos da Lei $n=8.112$, de 11 de dezembro de 1990, quanto a licenças e afastamentos para ações de desenvolvimento. Brasília: DOU, 2019.

BRASIL. Lei n.11.355, de 19 de outubro de 2006. Dispõe sobre a criação da Carreira da Previdência, da Saúde e do Trabalho [...]; e dá outras providências. Brasília: DOU, 2006.

CARBONE, P. P.; TONET, H. C.; BRUNO, J. R. S.; SILVA, K. I. B. Gestão por competências. São Paulo: FGV, 2016.

CASTRO, P. R.. IBGE já vem sendo alvo de ajustes há anos: entrevista concedida a Rafael Rosas, Robson Sales e Catherine Vieira. Rio de Janeiro: Jornal Valor Econômico, 2016.

COELHO, E. M.. Gestão do conhecimento como sistema de gestão para o setor público. Revista do Serviço Público, v.55, n.1-2, p. 89, 2004. DOI: https://doi.org/10.21874/rsp.v55i1-2.247 
DUTRA, J. S.. Gestão de pessoas: modelo, processos, tendências e perspectivas. 2 ed. São Paulo: Atlas, 2016

FERREIRA, P. I.. Gestão por Competências. Rio de Janeiro: LTC, 2015.

FLEURY, M. T. L.; FLEURY, A.. Construindo o conceito de competência. Rev. Adm. Contemp, Curitiba, v.5, p.183-196, 2001. DOI: https://doi.org/10.1590/S1415$\underline{65552001000500010}$

FONSECA, D. R.; MENESES, P. P. M.; SILVA FILHO; A. I.; CAMPOS, N. G.. Autonomia para gestão estratégica de pessoas no setor público federal: perspectivas de análise e agenda de pesquisas. Revista de Administração Pública, v.47, n.6, p.1451-1476, 2013. DOI:

https://doi.org/10.1590/S0034-76122013000600006

GHELMAN, S.; COSTA, S. R. R.. Adaptando o BSC para o setor público utilizando os conceitos de efetividade, eficácia e eficiência. In: SIMPÓSIO DE ENGENHARIA DE PRODUÇÃO, 12. Anais. Bauru, 2006.

GIL, A. C.. Como elaborar projetos de pesquisa. 6 ed. São Paulo: Atlas, 2017.

IBGE. Instituto Brasileiro de Geografia e Estatística. Avaliação de desempenho individual. Rio de Janeiro: IBGE, 2017.
LUCENA, M. D. S.. Planejamento estratégico e gestão do desempenho para resultados. São Paulo: Atlas, 2012.

MALHEIROS, B. T.; ROCHA, A. C.. Gestão de pessoas: avaliação e gestão de desempenho. Rio de Janeiro: LTC, 2014.

MARINELA, F.. Direito administrativo. 11 ed. São Paulo: Saraiva, 2017.

OLIVEIRA, K. P.; PAULA, A. P. P.. Herbert Simon e os limites do critério da eficiência na nova administração pública. Cadernos Gestão Pública e Cidadania, São Paulo, v.19, n.64, p.113-126, 2014. DOI:

http://dx.doi.org/10.12660/cgpc.v19n64.12605

PEREIRA, J. M.. Manual de gestão pública contemporânea. 5 ed. São Paulo: Atlas, 2016.

TAKAHASHI, A. R.. Pesquisa qualitativa em administração: fundamentos, métodos e usos no Brasil. São Paulo: Atlas, 2013.

VERGARA, S. C.. Projetos e relatórios de pesquisa em administração. 16 ed. São Paulo: Atlas, 2016.

YIN, R. K.. Estudo de caso: planejamento e métodos. 5 ed. Porto Alegre: Bookman, 2015.

A CBPC - Companhia Brasileira de Produção Científica (CNPJ: 11.221.422/0001-03) detém os direitos materiais desta publicação. Os direitos referem-se à publicação do trabalho em qualquer parte do mundo, incluindo os direitos às renovações, expansões e disseminações da contribuição, bem como outros direitos subsidiários. Todos os trabalhos publicados eletronicamente poderão posteriormente ser publicados em coletâneas impressas sob coordenação da Sustenere Publishing, da Companhia Brasileira de Produção Científica e seus parceiros autorizados. Os (as) autores (as) preservam os direitos autorais, mas não têm permissão para a publicação da contribuição em outro meio, impresso ou digital, em português ou em tradução. 